\title{
MODEL MATEMATIKA PENGELUARAN MINIMUM PADA HOME INDUSTRI SEPATU CIBADUYUT
}

\author{
Sayyidina Ganesha Heningputri, Rio Aurachman \\ Telkom University \\ Email: sayyidinaganesha@gmail.com, rioaurachman@telkomuniversity.ac.id
}

\begin{abstract}
Abstrak
Setiap minggunya industri rumahan Pak Mamat membuat tiga sepatu yaitu flat shoes, sepatu hak dan wedges. Pak Mamat harus memutuskan biaya pengeluaran minimum yang akan dikeluarkan untuk membeli bahan baku yang nantinya akan digunakan untuk membuat sepatu. Terdapat beberapa bahan baku yang digunakan oleh industri sepatu rumahan Pak Mamat yaitu insol, bahan semi kulit, fiber, hak, ujung keras, paku, spons, dan juga puring. Untuk membuat flat shoes, sepatu hak dan wedges bahan yang digunakan adalah sama hanya saja untuk sepatu jenis flat shoes penggunaan hak tidak digunakan. Bahan baku yang digunakan juga memiliki constraint untuk tiap tiap bahannya. Metode yang digunakan untuk mencari biaya minimum yang akan dikeluarkan untuk membeli bahan baku pembuatan sepatu adalah menggunakan pendekatan linier programming. Dengan bantuan software QM untuk mencari solusi dan iterasi simplex.
\end{abstract}

\section{Pendahuluan}

Riset operasional merupakan serangkaian kegiatan analisis dan pemodelan matematik untuk keperluan pengambilan keputusan. Banyak persoalan manajerial di suatu organisasi/ perusahaan yang senantiasa dikaitkan dengan proses pengambilan keputusan. Walaupun tujuan utamanya adalah untuk mendapatkan solusi, namun dalam prakteknya lebih dipentingkan solusi yang memuaskan. Analisis kuantitatif dan sistematik tetap dibutuhkan sebagai dasar argumentasi yang dapat dipertanggungjawabkan secara rasional. Penelitian Operasional ini juga revolusi besar dalam ilmu teknik industri. Yang mana ini digunakan untuk memaksimalkan sumber daya sehingga tujuannya adalah meminimalkan biaya yang telah menghabiskan dalam suatu bisnis. Ada banyak usaha kecil yang beroperasi di kota-kota besar, yang sama dengan pabrik besar di sebagian kecil daerah. Pada penelitian kali ini, akan dibahas rancangan untuk meningkatkan keuntungan dari penjualan sepatu di Home Industri kawasan Cibaduyut, Bandung.

Dalam industri pembuatan sepatu terdapat beberapa permasalahan dalam perindustriannya, salah satunya adalah biaya. Untuk mendapatkan untung biasanya para industri rumahan berinisiatif untuk mencari keuntungan minimal untuk membeli bahan baku industrinya. Oleh sebab itu, disini penulis membantu mencari solusi untuk membeli bahan baku dengan biaya terkecil.

Beberapa riset terdahulu telah menjadi referensi dalam melakukan pemodelan matematika [1]-[3] [4] [1], [4] [5]

\section{Perumusan Masalah}

Permasalahan adalah dibutuhkannya suatu formulasi yang terbaik untuk mendpatkan soludi biaya minimum yang akan dikeluarkan oleh suatu industri untuk mengeluarkan biaya minimum untuk membeli bahan baku. Pada kondisi sebelumnya, biaya yang dikeluarkan belumlah optimal. Rumusan 
masalah dari penelitian ini adalah "Bagaimana model matematika yang dapat memberikan solusi untuk mendapatkan biaya minimum untuk membeli bahan baku".

\section{Pemodelan Matematika}

Pada bab ini akan dipaparkan alur pemodelan matematika permasalahan dalam sistem nyata menjadi sebuah model matematika. Alur pemodelan diawali dengan pemodelan konseptual yang dilanjutkan dengan pemodelan matematika (Daellenbach dan McNickle, 2005).

\subsection{Model Konseptual}

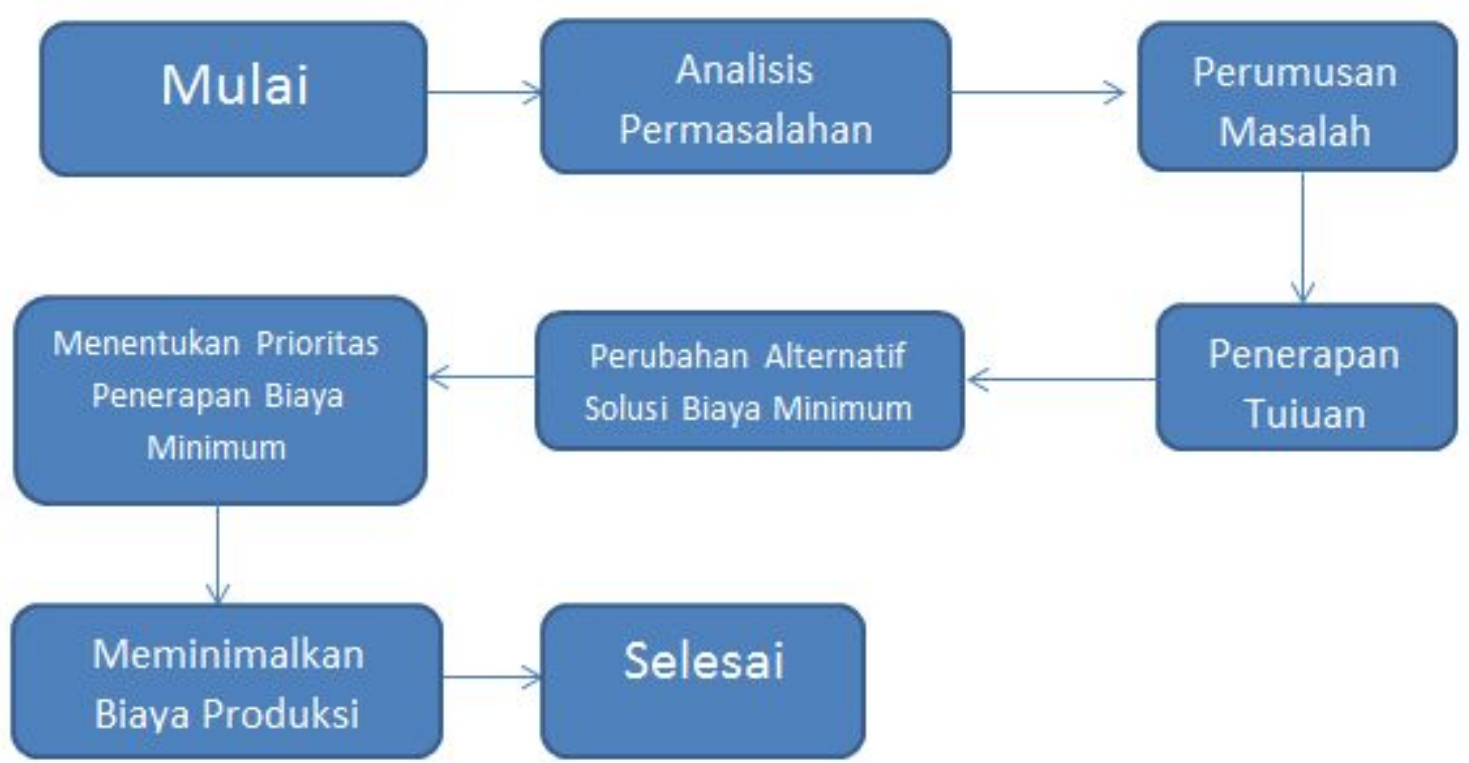

Model konseptual di atas dijadikan sebagai kerangka berpikir yang berbentuk flowchart yang saling berkaitan satu sama lain untuk mencapai tujuan tertentu.

Penelitian ini diawali dengan pemahaman terhadap pemahaman menganalisis masalah sesuai dengan materi Operational Research. Disini penulis akan menganalisis permasalahan meminimumkan biaya yang dikeluarkan oleh industri rumahan sepatu Pak Mamat. Kemudian merumuskan masalah dengan menentukan constraint dan variable dan kemudian ditentukan tujuan dari model matematika yang biasa disimbolkan dengan lambang Z. Pengukuran atas berapa biaya yang dikeluarkan untuk membeli bahan baku sepatu yang akan dibuat digunakan sebagai acuan dalam mencari solusi meminimasikan biaya yang akan dikeluarkan. Pada akhirnya akan didapat berapa biaya minimal yang akan dikeluarkan untuk memproduksi sepatu.

\subsection{Metode Pengumpulan Data dan Sumber Data}

Data yang penulis dapat bersumber dari wawancara langsung dengan Pak Mamat yang merupakan pemilik dari home industry sepatu yang terletak di Sentra Industri Sepatu Cibaduyut.

Data yang didapat dari wawancara tersebut kemudian diproses untuk dicari variable dan constraint nya. Tools yang digunakan untuk menyelesaikan permasalahan ini adalah linier programming.

\section{Model Matematika}

\subsection{Narasi Persoalan yang dihadapi}

Home Industry Pak Mamat memproduksi 3 jenis sepatu yaitu wedges, hak tinggi, dan flat shoes. Wedges dan sepatu hak diproduksi perminggunya sekitar 200 buah dengan memerlukan bahan baku sebesar Rp 166.000 dan sepatu flat shoes diproduksi perminggunya sekitar 400 buah dengan harga 
bahan baku Rp 136.000. Untuk memproduksi sepatu wedges, hak, dan sepatu flat shoes dibutuhkan bahan baku dengan rincian sebagai berikut:

\begin{tabular}{|c|c|c|c|c|}
\hline & & \multicolumn{3}{|c|}{ Biaya } \\
\cline { 3 - 5 } No & Bahan Baku & $\begin{array}{c}\text { Wedge } \\
\text { s }\end{array}$ & Hak & Flat Shoes \\
\hline 1 & Insol & 15000 & 15000 & 15000 \\
\hline & $\begin{array}{c}\text { Bahan semi } \\
\text { kulit }\end{array}$ & 25000 & 25000 & 25000 \\
\hline 2 & Fiber & 25000 & 25000 & 25000 \\
\hline 3 & & & 30.00 & \\
\hline 4 & Hak & 30.000 & 0 & 0 \\
\hline 5 & Ujung Keras & 15000 & 15000 & 15000 \\
\hline 6 & Paku & 20000 & 20000 & 20000 \\
\hline 7 & Spons & 12000 & 12000 & 12000 \\
\hline 8 & Puring & 24000 & 24000 & 24000 \\
\hline
\end{tabular}

\subsection{Penentuan Fungsi Tujuan, Parameter, Variabel, Constraint}

- Fungsi Tujuan : Minimasi baiaya pembelian bahan baku

- Parameter : Jumlah bahan baku dan harga bahan baku

- Variabel : $\mathrm{X}_{1}=$ Wedges, $\mathrm{X}_{2}=$ Hak, $\mathrm{X}_{3}=$ Flat shoes

- Constraint

- Batasan jumlah bahan baku

- Batasan harga bahan baku

\subsection{Model Matematika}

- Fungsi Tujuan

$\operatorname{Min} Z=200 X_{1}+200 X_{2}+400 X_{3}$

- Parameter

- Variabel

$\mathrm{X}_{1}=$ Wedges

$\mathrm{X}_{2}=$ Hak

$\mathrm{X}_{3}=$ Flat Shoes

- Constraint

$X_{1}+X_{2}+X_{3} \leq 45.000$

$X_{1}+X_{2}+X_{3} \leq 75.000$

$X_{1}+X_{2}+X_{3} \leq 45.000$

$X_{1}+X_{2} \leq 60.000$

$X_{1}+X_{2}+X_{3} \leq 45.000$ 
$X_{1}+X_{2}+X_{3} \leq 60.000$

$X_{1}+X_{2}+X_{3} \leq 36.000$

$X_{1}+X_{2}+X_{3} \leq 72.000$

$$
X_{1}, X_{2}, X_{3} \geq 0
$$

\section{Solusi dan Analisis}

\subsection{Proses Pencarian Solusi Menggunakan Software}

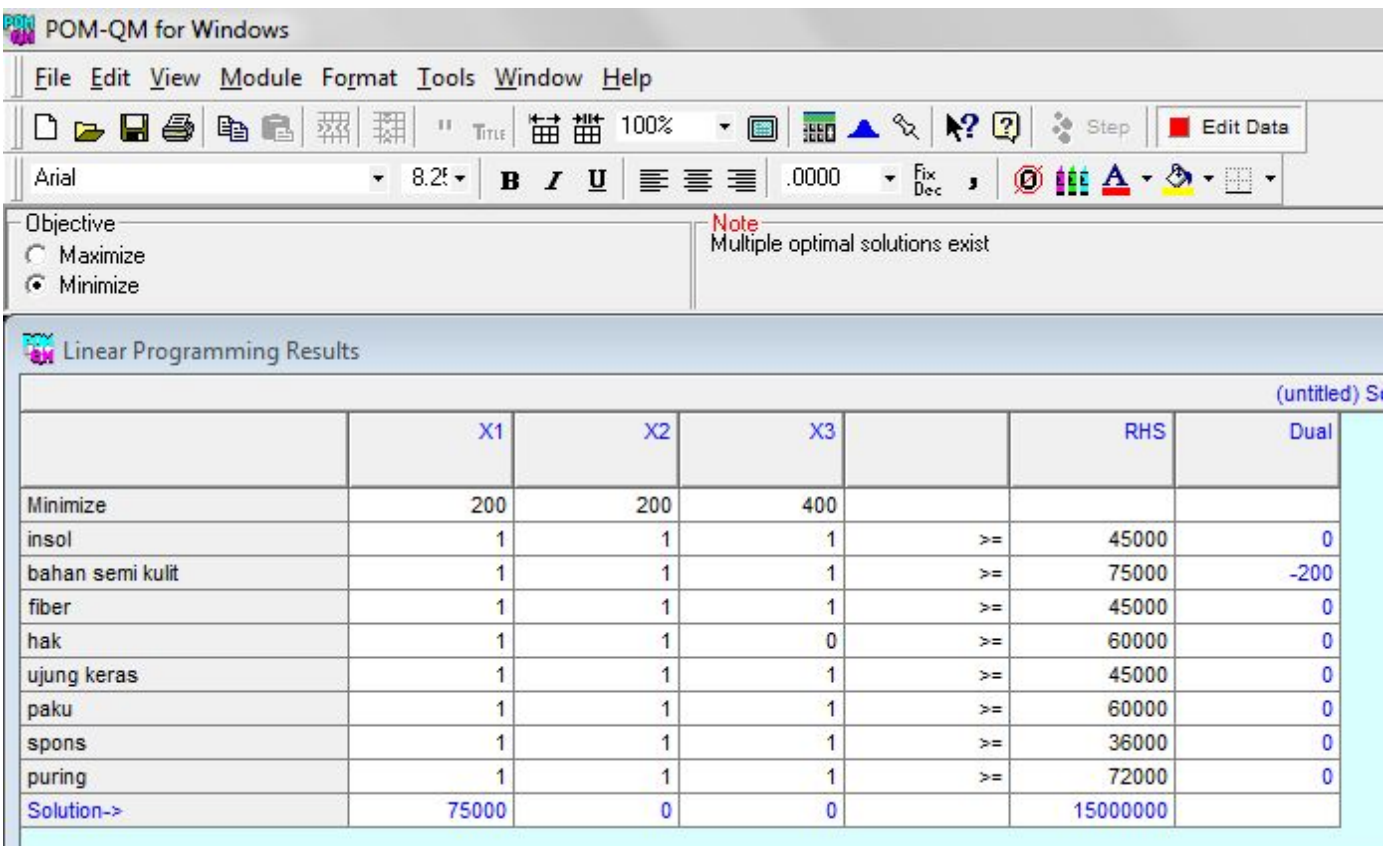

POM-QM for Windows

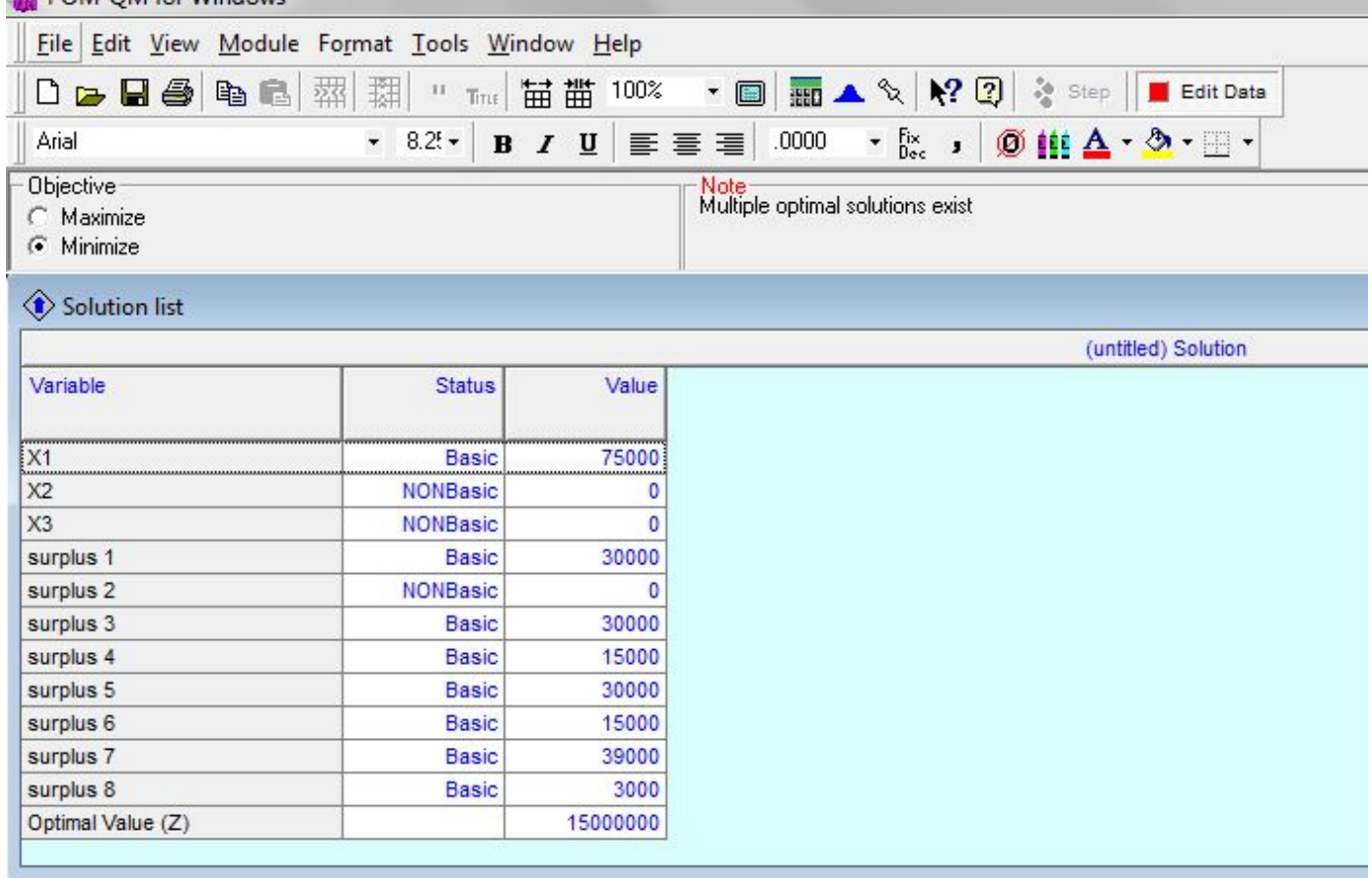

\subsection{Analisis Sensitifitas}


Penulis menggunakan software QM for Windows untuk menyelesaikan model matematika. Dari gambar di atas ditemukan solusi bahwa ongkos minimum yang dikeluarkan untuk membeli bahan baku yaitu sebesar Rp 15.000.000,- untuk memproduksi 200 wedges, 200 hak, dan 400 flat shoes dalam waktu satu minggu. Dari gambar di atas dinyatakan bahwa X2, X3, dan surplus 2 merupakan non basic yang memiliki nilai 0. Sedangkan X1, surplus 1, surplus 3, surplus 4, surplus 5, surplus 6, surplus 7, surplus 8 merupakan basis. Dengan solusi optimal (Z) sebesar 15.000 .000

\section{Kesimpulan}

Pengeluaran Pak Mamat paling minimum untuk membeli bahan baku adalah sebesar Rp 15.000.000,jika Pak Mamat membuat 200 buah sepatu wedges, 200 hak, dan 400 flat shoes per minggunya setelah dihitung menggunakan metode linear programming dengan software QM for Windows.

\section{Referensi}

[1] R. Aurachman, "Model Matematika Dampak Industri 4.0 terhadap Ketenagakerjaan Menggunakan Pendekatan Sistem,” Jurnal Optimasi Sistem Industri, vol. 18, no. 1. p. 14, 2019.

[2] T. P. Sari, A. Y. Ridwan, and R. Aurachman, "Designing Floor Tile Warehouse Layout Using Heuristic Approach Method to Increase Warehouse Capacity and Reduce Travel Distance," International Journal of Innovation in Enterprise System, vol. 1, no. 01. p. 44, 2017.

[3] E. G. B. Kuncoro, R. Aurachman, and B. Santosa, "Inventory policy for relining roll spare parts to minimize total cost of inventory with periodic review $(R, s, Q)$ and periodic review (R,S) (Case study: PT. Z)," IOP Conference Series: Materials Science and Engineering, vol. 453. p. $012021,2018$.

[4] N. I. Utama and R. Aurachman, “Jurnal Rekayasa Sistem \& Industri (JRSI),” vol. 5, no. 02. p. 85, 2018.

[5] A. K. Putra, A. Y. Ridwan, and R. Aurachman, "Design of Storage Allocation Using Interaction Frequency Heuristic-Order Oriented Slotting Approach to Reduce Delay Time on Traveling Searching Activities in Refinery Unit V Warehouse PT XYZ," Jurnal Rekayasa Sistem Industri, vol. 7, no. 1. p. 1, 2018. 